\title{
非农就业对南方集体林区不同规模林 农营林轮伐期的影响
}

\author{
朱 嫀 ${ }^{1,2}$, 徐志刚 ${ }^{3}$, 沈月琴 ${ }^{2}$, 占 菁 $^{4}$, 李博伟 ${ }^{1}$, 陈 梅 $^{1}$ \\ (1. 浙江农林大学经济管理学院, 临安 $311300 ; 2$. 浙江省重点培育智库, 浙江农林大学浙江省乡村振兴研究 \\ 院,临安 $311300 ; 3$. 南京农业大学经济管理学院, 南京 $210095 ; 4$. 开化县林业局, 开化 324300）
}

\begin{abstract}
摘要：在中国农村劳动力非农就业不断加速的背景下,探讨非农就业对集体林区不同规模林 农营林轮伐期的影响机制, 有助于明确不同规模经营主体今后的用材林营林目标和林业在山 区未来的经营发展模式, 同时为林业规模化经营的合理性提供客观依据。基于劳动力转移新 经济学理论, 通过对浙江、江西和福建三省 450 户林农的调查, 收集杉木营林的地块投人产出数 据, 在此基础上, 运用Faustmann模型计算规模户与普通户的理论最优轮伐期, 运用计量模型分 析非农就业对集体林区不同规模林农采伐轮伐期的影响机制。研究结果发现, 普通户和规模 户的理论最优轮伐期趋同; 非农就业的劳动力流失效应造成普通户营林的预期主伐时间显著 短于理论最优轮伐期, 而规模户非农就业带来的收人效应造成其采伐决策接近于理论最优轮 伐期。在农村非农就业不断增加背景下, 南方集体林区规模化经营的方式有利于接近最优采 伐决策,更适合于培育大径材,增加林业生态和经济效益。
\end{abstract}

关键词：新劳动力转移经济学;集体林区;采伐决策;非农就业;Faustmann模型

自 20 世纪 80 年代末林业 “三定” 以来，小规模、分散的家庭经营成了南方集体林区 林业生产经营制度的基本特征，据研究统计，南方集体林区林农的户均林地经营面积约 为 $1.8 \mathrm{hm}^{2}$ 。㞷。林地细碎化往往带来林农林业投资兴趣的下降, 林地生产率难以提升 ${ }^{[2-3]}$ 。 另一方面, 自 20 世纪 90 年代以来, 城市化加速和产业间比较优势的存在导致农村大量青 壮年劳动力转向城市及非农部门 ${ }^{[4]}$ 。近年来农村外出务工人数年均增长率始终保持在 $0.6 \%$, 到 2016 年末农村外出务工人数更达到了 1.5 亿 $^{[5]}$, 这直接造成农村林业劳动力要素 供给稀缺和质量下降, 林业劳动力机会成本不断上升。这对于以丘陵地带为且主机械替 代率低的南方集体林区而言, 更进一步加剧了提升集体林区林地生产率的难度。自集体 林权改革进人全面深化阶段开始, 林业规模化经营越来越被南方集体林区视为解决提升 林地生产率的主要路径 ${ }^{[6] 2016}$ 年, 国务院办公厅印发了《国务院办公厅关于完善集体 林权制度的意见》(国办发（2016）83号)，进一步鼓励林业适度规模经营。但无论对于 普通户还是规模户而言, 在大量农村劳动力非农化转移背景下, 都将强化其家庭劳动力

收稿日期：2018-07-09; 修订日期：2018-11-26

基金项目：国家自然科学基金项目（71773116）；浙江省科技厅软科学项目（2017C35054）; 浙江省社科规划 “之江 青年课题”项目 (16ZJQN044YB)

作者简介: 朱臻 (1980-), 男, 浙江嘉兴人, 副教授, 硕士生导师, 研究方向为林业经济、资源与环境经济。 E-mail: zhuzhen8149278@126.com

通讯作者: 沈月琴 (1964-), 女, 浙江湖州人, 教授, 博士生导师, 研究方向为林业经济理论与政策。

E-mail: shenyueqin-zj@163.com 
约束，同时也会放松其收人约束，这就会对不同规模林农的营林预期决策行为带来影 响。在农户用材林经营的预期决策行为中，其最重要一环是对采伐时间的决策判断。一 方面, 采伐环节需要大量劳动力和资本要素投人, 这与非农就业存在一定冲突; 另一方 面，采伐时间确定也影响到农户营林选择目标（如培育大径材还是速生材）和产出效 益。虽然在家庭劳动力流动性约束下, 无论是对规模户还是普通户而言, 都可通过雇工 或购买社会化服务来满足营林采伐的劳动力需求，但由于农户之间营林规模差异和农村 劳动力价格的逐年上涨，会导致不同规模林农对劳动力的需求和成本投人之间存在差 异，在不同规模林农的资源禀赋和林业收人依赖性存在差异的背景下，又会对不同规模 林农的营林培育目标及其采伐期的确定产生差异性影响。因此对该问题进行讨论，在非 农劳动力转移就业加速和用材林仍然作为南方集体林区主要营林林种的现实背景下, 将 有助于明确集体林区不同规模经营主体的用材林营林目标和林业作为弱势产业在山区未 来的经营模式，同时为林业规模化经营合理性和保障木材安全提供客观依据。

国内外对于非农就业对农户行为决策研究主要集中在农业经济领域，包括非农就业 对农地流转行为研究 ${ }^{[7-8]}$, 以及非农就业对农林业生产性投资和要素配置影响研究 ${ }^{[9-10]}$, 一 般存在两类观点。有学者认为, 非农就业所带来收人效应增加会促使农户追加农林业生 产投资, 如购买替代缺失劳动力的资产和机械服务投资 ${ }^{[1-12]}$ 。但也有学者认为农村劳动力 外出转移就业对农户家庭的农业生产投资没有作用，甚至会带来负向影响 ${ }^{[13-14]}$ 。针对非农 就业对林业生产决策影响研究同样主要集中于要素投人行为领域, 大部分学者认为非农 就业带来了林业生产性投资减少 ${ }^{[15]}$ 。在采伐预期决策讨论领域, 最早对采伐决策行为讨 论来自对最优轮伐期理论上的探讨 ${ }^{[16]}$ 。国外学者也用实证研究证明农户非农收人的增多 会导致农户开展营林的机会成本增加, 继而导致采伐量的减少 ${ }^{[17-18]}$, 国内森林经理领域学 者基于不同树种小班数据采用Faustmann模型、动态规划方法或 GIS 测算最优轮伐期以讨 论用材树种最优采伐决策 ${ }^{[19-20]}$ 。在林业经济领域, 有学者结合最优轮伐期模型从理论上设 计了中国林业经济政策的分析框架 ${ }^{[2]]}$, 还有学者则主要从林权改革角度, 讨论其对于采 伐决策的影响[22]。在森林碳汇被作为缓解全球气候变化的有效途径背景下, 诸多国内外 学者设计和讨论了结合碳汇收益的农户采伐决策模型 ${ }^{[23-24]}$ 。但讨论非农就业与林农采伐决 策关系的国内研究明显缺乏。

\section{1 研究方法与数据来源}

\section{1 分析框架}

现有国内外相关研究从 20 世纪 80 年代开始采用 Stark 等 ${ }^{[25]}$ 提出的劳动力转移新经济 学模型（The New Economics of Labor Migration, 简称 NELM）来回答非农就业背景下 农户的农林业生产决策行为问题。NELM 理论是用投资组合和契约安排理论解释劳动力 迁移行为与家庭决策的关系, 认为农户外出务工的决策是对劳动力等资源要素的重新分 配 ${ }^{[26]}$ 。从 NELM 理论出发, 分析劳动力转移对林农营林生产决策行为影响, 主要考虑两 个方面的综合效应作用。一是 “劳动力流失效应”, 即由于劳动力非农化所带来的营林劳动 力流失。从普通农户考虑, 家庭务农劳动力的流失不但会使得农村家庭中传统的农业互 助行为活动减少, 而且会使得农林业生产更加粗放, 甚至出现抛荒情况 ${ }^{[27-28]}$ 。二是 “收人 
效应”，即农户可从家庭劳动力的非农专业就业中获得汇款收人。非农收人的增加将使农 户的主要生计行为发生变化, 导致农户减少林业投资 ${ }^{[20]}$, 也有可能促使其用增加的非农收 人更多地购买农药、化肥等农业生产要素, 为农林业投资增加便利 ${ }^{[30]}$ 。从本文视角出 发, 由于不同规模林农在资源禀赋差异和劳动力流动性约束的区别, 会导致非农就业对 其采伐决策行为存在差异。假设某林农面临两种可能的生产活动选择，即劳动力投资报 酬率较高且较快的非农就业活动和劳动力投资报酬较低且较慢的营林活动。林农需将家 庭初始资源禀赋要素拥有量 $\bar{W}$ (如劳动力和资本要素) 分别投人到非农和营林两类生产 活动中。林农需要在非农就业可获得的短期效益和营林活动长期效益间配置资源要素使 其目标函数效用达到最大化，具体见式 (1):

$$
\operatorname{Max}_{L_{j} T_{o}} U=U\left(I_{o}, \pi_{f}, N, H\right)
$$

式中： $U$ 效用包括了林农通过营林活动在轮伐期 $T$ 内可得到的预期利润贴现值（ $\left.\pi_{f}\right)$ 和当 期通过非农就业活动获得非农收人 $\left(I_{o}\right)$ 所带来的效用; $N$ 代表林农闲置时间； $H$ 代表影 响林农效用偏好的其他影响因素。 $L_{j}$ 代表配置到非农就业或营林活动的家庭劳动力。同 时，笔者用 $W_{1}$ 表示农户投资于非农就业的资源禀赋要素，而 $W_{2}$ 表示林农投资于营林活动 的资源禀赋要素, 其要素投人受到非农就业资源要素投人制约, 可用 $W_{2}=g(m, r)$ 来表 示, 其中 $r$ 表示非农就业带来的汇款收人增加的 “收人效应”，而 $m$ 表示非农就业带来的 家庭营林劳动力减少的 “流失效应”。则非农就业的收人函数 $I_{o}$ 和营林活动的预期利润函 数 $\pi_{f}$ 可用式 (2) 和式 (3) 表示:

$$
\begin{gathered}
I_{o}=f\left(W_{1}, H\right)=f\left(L_{o}, C_{o}, H\right) \\
\pi_{f}=\int_{T}\left(P_{f} f\left(W_{2}, H\right)-C\right) \mathrm{d} t=\int_{T}\left(P_{f} f(g(m, r), H)-C\right) \mathrm{d} t \\
=\int_{T}\left(P_{f} f\left(L_{f}, S, C_{f}, H\right)-w L_{f}-\gamma S-\varphi C_{f}\right) \mathrm{d} t
\end{gathered}
$$

其约束条件包括式（4） 式 (6):

$$
\begin{gathered}
\bar{W}=W_{1}+W_{2} \\
T-N=\sum_{j} L_{j}, \text { 其中 } j=o, f \\
\frac{\partial W_{2}}{\partial S}>0
\end{gathered}
$$

式中: 林农家庭的非农收人 $I_{o}$ 与该家庭在非农就业上的资源要素投人 $W_{1}$ 和林农效用偏好 $H$ 相关。其中, 林农家庭在非农就业上的资源要素投人 $W_{1}$ 包括了在非农就业上的劳动力 要素投入 $L_{o}$ 和资本要素投入 $C_{o}$ 。在式 (3) 中, 林农营林的预期利润目标函数 $\pi_{f}$ 与林农营 林中的要素投人 $W_{2}$ 、林农效用偏好 $H$ 和营林成本 $C$ 直接相关。考虑到营林长周期性的特 点, 因此在轮伐期 $T$ 下的林农预期营林利润函数用贴现形式表示。从劳动力转移新经济 学理论出发, 林农营林中的要素投人 $W_{2}$ 受到非农就业带来的劳动力 “流失效应” 和非农 就业的 “收人效应” 影响。 $W_{2}$ 包括了营林劳动力投人 $L_{f}$ 、林地投入要素 $S$ 和营林投人资 本 $C_{f}$ 来表示 $(w, \gamma, \varphi$ 分别代表劳动力、林地和资本的要素价格)。这里假设林产品市场是 一个完全竞争市场，其林产品价格 $P_{f}$ 是外生的，式（4） 式（6）是营林预期利润目标函 数的约束条件, 包括林农要素投人和家庭时间配置的约束条件。其中式 (5) 为林农家庭 成员在营林轮伐期 $T$ 内，要么将时间配置到营林或非农就业等生产活动上，要么将时间 
配置到闲暇活动 $N$ 上。式（6）表示林农营林面积的增加会对家庭营林投人和收人产生正 向影响。基于上述理论模型的构建，比较不同规模林农家庭劳动力在非农就业和营林活 动中劳动力配置所带来的边际收益, 从而分析不同规模林农非农就业对其采伐决策行为 的影响。从普通户出发, 由于其营林规模小, 且营林周期长所造成的风险性, 使其营林 的预期利润贴现值较小，则该类农户投人非农就业劳动力所带来的边际收益高于将劳动 力投人到营林活动的边际收益 (即 $\frac{\partial I_{o}}{\partial L_{o}}>\frac{\partial \pi_{f}}{\partial L_{f}}$ ), 因此普通户会在亟需要素投人的营林初 始阶段反而将更多的要素尤其是劳动力要素投人到非农就业中, 即非农就业带来的劳动 力 “流失效应” 造成轮伐期缩短 $\left(\frac{\partial T}{\partial m}<0\right)$; 而对于规模户而言, 由于营林面积增加导 致劳动力的边际产出下降速度减缓, 约束条件 $6\left(\frac{\partial W_{2}}{\partial S}>0\right.$, 即随着营林面积的增加要素 投人增多）导致其预期营林利润贴现值增加，这就让规模户投人营林的劳动力边际收益 高于非农就业带来的劳动力边际收益 (即 $\frac{\partial I_{o}}{\partial L_{0}}<\frac{\partial \pi_{f}}{\partial L_{f}}$ ) 成为可能, 那么在家庭劳动力资源 稀缺的背景下，规模户会通过非农就业收人购买资源禀赋要素配置到营林生产中，即非 农就业 “收人效应” 会造成营林轮伐期的延长（ $\left.\frac{\partial T}{\partial r}>0\right)$ 。由上述分析可以发现，非农 就业对不同规模林农营林采伐期影响的作用机制是存在差异性的。

\section{2 案例点选择和数据来源}

考虑到不同用材林树种的主伐年龄存在区别，研究分析不同规模林农的采伐决策问 题, 首先需要确定具体的用材树种。杉木 (Cunninghamia) 是南方首要的速生商品材树 种。据第八次森林资源清查, 杉木的人工种植面积达到 1096 万 $\mathrm{hm}^{2}$, 占中国乔木林面积 的 6.7\% , 蓄积量达到 7.3 亿 $\mathrm{m}^{3}$, 在南方集体林区中杉木林面积之和占全国总面积的 $89.83 \%{ }^{[3]]}$ 。鉴于林业经营项目的复杂性和多样性，将杉木这一南方集体林区首要商品用 材树种作为本文案例树种, 可以尽量保证大样本的数据比较, 以确保研究目标实现。针 对研究问题和案例树种, 调查组在 2016年通过典型抽样方法选取南方集体林区浙江、江 西和福建 3 个省份作为样本省开展农户调查。三省位于中国东南沿海, 森林覆盖率和集 体林比例分别在 $60 \%$ 以上和 $85 \%$ 以上，是典型的南方集体林区。三省杉木林面积分别达 到 82.1 万 $\mathrm{hm}^{2} 、 126.1$ 万 $\mathrm{hm}^{2}$ 和 259.2 万 $\mathrm{hm}^{2}$, 分别占全省林地面积的 $12.4 \% 、 24.6 \%$ 和 $13.8 \%$ 。在浙江、江西和福建 3 个样本省的重点林区县（市）内按照农民人均可支配收人 差异, 运用分层抽样方法选取了样本县 ${ }^{\mathbb{1}}$, 其中在浙江省共抽取 5 个样本县, 而由于在江 西和福建两省杉木营林地区相对集中, 因此各抽取了 3 个样本县。进一步, 采取分层抽 样方法在每个样本县内各选取 3 个乡镇, 并在每个乡镇内各选取两个样本村。最后共计 在浙江省抽取了 15 个乡镇，30个村，而在江西、福建两省共抽取 9 个乡镇，18 个村。最 后在样本村中，为了有效区分规模户与普通户，调查组首先通过村访谈了解不同样本村 户均林地面积。为了体现规模户的特点同时确保一定规模户样本，将营林面积为本村户

(1) 根据 2015 年农民人均可支配收人指标进行分层抽样。本文选取的 11 个样本县平均森林覆盖率在 $74.9 \%$ 左右, 其中浙江省 5 个样本县市平均森林覆盖率 $73 \%$, 江西省 3 个样本点平均森林覆盖率 $74 \%$, 福建样本县森林覆盖率 $79 \%$ 。所选样本县市皆为重点林区和用材林基地。 
均林地面积 3 倍以上农户界定为规模户，而将其他农户界定普通户口。考虑到普通户数量 远大于规模户数量的现实情况, 因此在每个样本村分别在普通户中随机抽取了 7 户普通 户样本，在规模户中随机抽取 3 户规模户样本。剔除非杉木经营和营林周期信息缺失的林 农样本，林农有效样本为 450 户，其中包括规模户 138 户和普通户为 312 户。在农户调查 中，重点了解不同规模林农家庭基本特征、2015年从事非农就业情况（包括非农就业时 间及非农收人等）及家庭营林情况。为较为全面了解杉木一个周期营林投人产出情况， 考虑到营林周期长、投人阶段较集中（主要发生在初始投人阶段）且在不发生技术革新 情况下要素投人量基本保持稳定, 为确保研究目标实现和数据之间可比性, 调查组要求 林农依据自身营林经验和家庭现有劳动力配置情况，以 2015 年为基年，估计杉木最大地 块完整一个营林周期的要素投人产出情况以及预期主伐时间，为测算理论最优轮伐决策 奠定基础。

\section{3 模型设计}

\subsection{1 理论最优轮伐期测算模型}

林农的采伐决策直接关系到营林周期长短和木材培育的目标，理论上针对不同规模 林农营林都存在一个理论最优轮伐期。但现实上受到各种因素影响，林农的预期采伐时 间会与这一理论最优轮伐期存在一定的差异。因此本文重点讨论不同规模林农由于非农 就业造成的对预期采伐时间与理论最优轮伐期离差的影响。

(1)杉木生长模型

要计算林地期望收益最大化下的轮伐期, 需要了解不同树龄下杉木的理论生长模拟 数据。国内学者开展了大量的杉木生长模型构建和最优轮伐期的研究 ${ }^{[20,32]}$ 。为测算杉木不 同生长年份的蓄积量且考虑变量的易获取性, 采用陈则生 ${ }^{[3]}$ 设计的生长模型, 其生长模 型可以表示为式 (7):

$$
M=b_{1} S I^{b_{2}}[1-\exp (-k t)]^{c}
$$

式中: $M$ 为杉木蓄积量 $; S I$ 为立地指数; $t$ 为林分年龄。 $b_{1}=4.53547 ; b_{2}=1.60931$; $c=3.720004 ; k=0.096004$ 。立地指数 $S I$ 按照立地条件好、中、差分别设定为 $16 、 12 、 8^{[33]}$ 。

由于木材是根据胸径不同制定相应木材价格，为确定不同龄级木材市场价格，需采用 杉木平均胸径和树高模型测算，同样采用陈则生 ${ }^{[32}$ 的胸径和树高模型：

$$
\begin{gathered}
\bar{D}=1.77871 S I^{1.38791}[1-\exp (-0.011672 t)]^{0.80127} \\
\bar{H}=14.8032 S I^{0.42132}[1-\exp (-0.00942 t)]^{0.76261}
\end{gathered}
$$

式中： $\bar{D}$ 表示杉木平均胸径; $\bar{H}$ 表示杉木平均树高。

\section{(2)Faustmann模型}

本文采用 Faustmann 模型测算不同规模林农杉木营林的最优轮伐期，Faustmann ${ }^{[16]}$ 在 考虑土地机会成本基础上假定土地一直重复用来生产木材，把所有未来收益都占现到现 在的价值，其总贴现价值就相当于土地的价值，以此来确定木材最优轮伐期。具体公式 如下：

$$
L E V=\operatorname{Lim}_{n \rightarrow \infty} \operatorname{Max}_{T, E}\left[p_{T} Q(T, E)-w E \mathrm{e}^{r T}\right]\left(\mathrm{e}^{r T}-1\right)^{-1}
$$

(2) 对于规模户与普通户界定各地区有很大的差异，笔者采用的此类界定规模户与普通户的方法主要考虑到不同 地区区分规模户的面积指标存在一定差异, 很难以单独一个面积数量指标来衡量规模户和普通户区别。 
式中： $L E V$ 代表林地的期望值; $p_{T}$ 为木材价格; $E$ 为要素投人量; $w$ 为要素投人价格 ${ }^{3} ; r$ 为市场贴现率 (以 2015 年国内主要银行平均 1 年期存款利率 $2 \%$ 作为年贴现率); $T$ 为轮 伐期。其中当 $L E V$ 达到最大值，对应的轮伐期即为最优轮伐期。

\subsection{2 计量模型的设计}

为了进一步解释非农就业对不同规模林农营林轮伐期的影响机制, 需要建立计量模 型加以分析，其多元回归模型形式如下：

$$
T_{i}=\alpha_{0}+\varphi \text { Loff }_{i}+\text { LLand }_{i}+\lambda \text { Policies }_{i}+\gamma X_{i t}+\varepsilon_{i}
$$

式中: 被解释变量为 $T_{i}$, 表示林农 $i$ 在其最大经营地块的预期主伐时间与理论最优轮伐期 的离差。关键解释变量中, Loff $i$ 是衡量林农 $i$ 家庭 2015 年的非农就业情况变量, 变量包括 农户家庭是否为非农就业户（家庭人均非农就业时间连续超过 1 个月以上的认为是非农 就业户） ${ }^{4}$ ，该指标反映非农就业所带来的总效应对于不同规模林农营林轮伐期的影响， 其次选取家庭成员户均非农劳动力就业时间和家庭人均非农收人水平用以反映林农非农 就业带来的劳动力流失效应和收人效应分别对于不同规模林农营林轮伐期的影响。控制 变量 $L^{2} d_{i}$ 表示林农 $i$ 最大地块经营特征，包括该地块面积大小、地块离最近公路距离 (用以反映地块经营便利性)、该地块权属是否为承包山（采用虚拟变量用以反映林农地 块经营的产权安全性， $1=$ 是； $0=$ 否）、该地块种植密度（用来反映杉木经营强度和技术 手段)、地块立地条件（用以反映土地立地质量）。Policies s $_{i}$ 为政策变量，用虚拟变量反映 林农 $i$ 是否享受到林业补贴政策（1=是； $0=$ 否)，外部政策扶持将有效促进林农营林积极 性。 $X_{i}$ 代表其他控制变量，包括林农家庭社会特征（户主年龄、受教育程度、家庭林业 收人所占比例和家中是否有人担任村干部）和区域虚拟变量，分别用来反映区域所造林 地差异； $\varepsilon_{i}$ 为符合独立同分布随机扰动项。

\section{2 描述性统计分析}

\section{1 不同规模林农的家庭特征及杉木营林投入产出分析}

对三个样本省规模户和普通户基本特征进行了对比和统计检验分析（表 1)。三省样 本户户主平均年龄在 53.5 岁，其中浙江省户主平均年龄最高达到 56.2 岁 ; 三省林农户主 平均文化程度接近初中水平，表明农民文化程度普遍偏低。随着山区非农就业转移增 加，林农家庭非农收人比例不断增高，2015 年三省样本户平均非农收人占家庭总收人比 例达到 $67.3 \%$ ，户均非农劳动时间达到 6.3 个月。其中在社会经济发达的浙江省，林农家 庭样本户均非农收人占家庭总收人比例达到 74.7\% , 户均非农劳动时间达到 6.9 个月，且 户均非农收入超过了 5 万元。从普通户和规模户对比来看，规模户由于拥有的家庭资源 禀赋更为丰富，所从事的非农就业报酬率普遍高于普通户，导致三省平均规模户户均非

(3) 测算林地期望值需要对应不同胸径的木材价格，本文收集了 2015 年案例省木材平均价格。三省的木材市场价 格基本类似，保持在胸径 $6 \mathrm{~cm}$ 以下 300 元 $\cdot \mathrm{m}^{-3} ; 6 \sim 8 \mathrm{~cm}$ 之间为 800 元 $\cdot \mathrm{m}^{-3} ; 8 \sim 12 \mathrm{~cm}$ 之间为 850 元 $\cdot \mathrm{m}^{-3} ; 12 \sim 16 \mathrm{~cm}$ 之间为 900 元 $\cdot \mathrm{m}^{-3} ; 16 \sim 20 \mathrm{~cm}$ 之间为 900 元 $\cdot \mathrm{m}^{-3} ; 20 \mathrm{~cm}$ 以上为 1100 元 $\cdot \mathrm{m}^{-3}$ 。

(4) 对于如何确定农户是否非农就业, 不同研究和统计有不同的分类方法, 主要根据农户是否有非农收人来源来 区分。从本次农户调查来看, 一个月以内的非农就业农户一般选择在离家距离较近的地区或者就在本村以零工为 主，因此如果将这部分农户归为非农就业农户就无法真实识别出非农就业对营林劳动力带来的时间分配效应。因此 本文选择人均非农就业时间持续在一个月以上作为非农就业户，此类农户在三省往往与工作单位签订劳动合同，属 于相对正式、稳定的非农就业户。 
表 12015 年 3 个省样本户家庭和营林基本特征描述性统计

Table 1 The descriptive statistics of household samples in three case provinces in 2015

\begin{tabular}{|c|c|c|c|c|c|c|c|c|c|c|c|}
\hline 省份 & $\begin{array}{l}\text { 林农 } \\
\text { 类型 }\end{array}$ & $\begin{array}{c}\text { 户主平 } \\
\text { 均年龄 } \\
\text { (岁) }\end{array}$ & $\begin{array}{c}\text { 户均家庭 } \\
\text { 非农收人 } \\
\text { (元) }\end{array}$ & $\begin{array}{c}\text { 户均非农 } \\
\text { 劳动时间 } \\
\text { (月) }\end{array}$ & $\begin{array}{c}\text { 户均林业 } \\
\text { 收人占 } \\
\text { 家庭收人 } \\
\text { 比例 }(\%)\end{array}$ & $\begin{array}{c}\text { 户均 } \\
\text { 营林面积 } \\
\left(\mathrm{hm}^{2}\right)\end{array}$ & $\begin{array}{c}\text { 平均最大 } \\
\text { 地块面积 } \\
\left(\mathrm{hm}^{2}\right)\end{array}$ & $\begin{array}{c}\text { 最大地块 } \\
\text { 离公路 } \\
\text { 平均距离 } \\
(\mathrm{km}) \\
\end{array}$ & $\begin{array}{l}\text { 最大地块 } \\
\text { 单位面积 } \\
\text { 种植密度 } \\
\left(\text { 株 } \cdot \mathrm{hm}^{2}\right)\end{array}$ & $\begin{array}{l}\text { 最大地块 } \\
\text { 预期采伐 } \\
\text { 时间(年) }\end{array}$ & $\begin{array}{c}\text { 享受林业 } \\
\text { 补贴政策 } \\
\text { 比例 }(\%)\end{array}$ \\
\hline \multirow{4}{*}{$\begin{array}{l}\text { 浙 } \\
\text { 江 } \\
\text { 省 }\end{array}$} & 普通户 & 56.7 & 43026 & 8.7 & 15.0 & 2.2 & 0.9 & 1.7 & 3406 & 16.8 & 31.0 \\
\hline & 规模户 & 54.9 & 70904 & 5.2 & 25.4 & 31.3 & 9.5 & 1.7 & 2637 & 21.1 & 61.5 \\
\hline & $T$ 均值检验 & 1.6 & $-4.3^{* * *}$ & -0.1 & $-3.1^{* * *}$ & $-10.9^{* * * *}$ & $-7.1^{* * *}$ & -0.1 & $5.7^{* * *}$ & $-2.1^{* *}$ & $-5.2^{* * *}$ \\
\hline & 全部 & 56.2 & 52086 & 6.9 & 18.2 & 11.0 & 3.5 & 1.7 & 3173 & 18.9 & 40.2 \\
\hline \multirow{4}{*}{$\begin{array}{l}\text { 福 } \\
\text { 建 } \\
\text { 省 }\end{array}$} & 普通户 & 50.1 & 28206 & 8.2 & 26.4 & 2.3 & 1.4 & 2.7 & 3126 & 18.8 & 16.0 \\
\hline & 规模户 & 45.8 & 50385 & 1.5 & 53.1 & 24.1 & 6.7 & 1.8 & 2606 & 21.1 & 29.2 \\
\hline & $T$ 均值检验 & $1.7^{*}$ & -1.5 & $1.83^{*}$ & $-3.3^{* * *}$ & $-5.2^{* * * *}$ & $-5.4^{* * *}$ & 1.2 & $2.9^{* * * *}$ & $1.80^{*}$ & -1.3 \\
\hline & 全部 & 48.7 & 35399 & 4.9 & 35.0 & 9.4 & 3.1 & 2.4 & 2958 & 19.9 & 20.3 \\
\hline \multirow{4}{*}{$\begin{array}{l}\text { 江 } \\
\text { 西 } \\
\text { 省 }\end{array}$} & 普通户 & 48.5 & 20475 & 8.0 & 12.4 & 1.6 & 0.5 & 2.2 & 3592 & 17.5 & 30.8 \\
\hline & 规模户 & 46.4 & 35783 & 4.1 & 25.0 & 21.4 & 6.2 & 3.5 & 2638 & 21.9 & 39.1 \\
\hline & $T$ 均值检验 & 0.9 & $-1.77^{*}$ & -0.09 & $-2.1^{* * *}$ & $-2.7^{* * *}$ & $-3.7^{* * *}$ & -1.1 & $2.8^{* * * *}$ & 0.48 & -0.7 \\
\hline & 全部 & 47.9 & 25169 & 6.0 & 16.2 & 7.7 & 2.2 & 2.6 & 3300 & 19.7 & 33.3 \\
\hline \multirow{4}{*}{$\begin{array}{l}\text { 总 } \\
\text { 体 }\end{array}$} & 普通户 & 54.3 & 35920 & 8.2 & 16.4 & 2.1 & 0.9 & 1.9 & 3392 & 17.7 & 28.5 \\
\hline & 规模户 & 51.9 & 61482 & 4.4 & 30.1 & 28.4 & 8.4 & 2.0 & 2632 & 21.4 & 52.2 \\
\hline & $T$ 均值检验 & $2.4^{* * *}$ & $-4.4^{* * *}$ & 0.7 & $-4.8^{* * *}$ & $-11.6^{* * *}$ & $-8.7^{* * *}$ & -0.3 & $6.9^{* * * *}$ & -1.24 & $-4.9^{* * *}$ \\
\hline & 全部 & 53.5 & 43759 & 6.3 & 20.6 & 10.2 & 3.2 & 2.0 & 3159 & 19.5 & 35.8 \\
\hline
\end{tabular}

注： “" “"”分别代表在 $10 \% 、 5 \% 、 1 \%$ 水平上显著; 数据来源于农户调查，下同。

农收人在 $1 \%$ 水平上显著高于普通户，尤其在浙江省规模户户均非农收人是普通户的 1.6 倍; 但从收人依赖性来看，规模户由于营林规模较大，其户均林业收人占家庭收人比例 则在 $1 \%$ 水平上显著高于普通户。而普通户由于劳动力资源相对稀缺，导致其更愿意从事 收益较高的非农就业工作，三省普通户非农劳动时间高于规模户 3.8 个月，从而导致了三 省普通户非农收人占林农家庭比例都要高于规模户，尤其在福建省普通户非农收人占林 农家庭比例比规模户高 $17.1 \%$ 。样本户户均营林面积和最大地块面积分别为 $10.2 \mathrm{hm}^{2}$ 和 $3.2 \mathrm{hm}^{2}$, 其中规模户户均营林面积和最大地块面积在 $1 \%$ 水平上显著大于普通户, 分别是 普通户的 14 倍和 9.3 倍, 而三省普通户的平均种植密度则都显著高于规模户，这可能与 其经营目标相关（规模户主要发展大径材为主; 而普通户则由于营林面积小强调密植, 发展中小径材为主）。三省规模户预期主伐时间相对于普通户的主伐时间晚近 3.7 年。三 省规模户享受林业补贴的比例显著高于普通户，进一步验证了目前政府营林扶持政策倾 向于规模户这一事实。

本文以 2015 年为基年，按目前林农劳动力配置情况收集了一个轮伐期中投人产出数 据, 并以 2015 年要素市场价格贴现测算规模户与普通户一个营林轮伐期营林投人和利润 净现值（如上以 $2 \%$ 作为年贴现率）, 并进行对比和统计检验（表 2$)$ 。从营林生产过程来 看，在单个轮伐期内，林农的经营成本主要包括 3 个部分 ${ }^{5}$ : (1) 种植成本。包括第一年 林地整理、种植、施肥和补植的用工成本以及种苗、化肥等生产资料成本。从表 2 中发

(5) 需要注意的是表 2 中按照成本投入阶段划分的成本总和不等于单位面积总成本，因为不包括地租成本。规模户的 地租价格以最大块林地的流转价格来计算, 而普通户的地租价格则以所在村的林地平均价格作为影子价格来计算。 
表 2 不同规模林农最大地块一个经营轮伐期内的营林投入和收入净现值统计

Table 2 The net value of inputs and incomes of a forest management circle in the largest plot of households

\begin{tabular}{|c|c|c|c|c|c|c|c|c|c|}
\hline \multirow[b]{2}{*}{ 省份 } & \multirow[b]{2}{*}{ 类型 } & \multicolumn{3}{|c|}{ 单位面积成本投人阶段划分 } & \multicolumn{2}{|c|}{ 单位面积成本结构划分 } & \multirow[b]{2}{*}{$\begin{array}{c}\text { 单位面积 } \\
\text { 总成本 } \\
\left.\text { (元 } / \mathrm{hm}^{2}\right)\end{array}$} & \multicolumn{2}{|c|}{ 单位面积产出 } \\
\hline & & $\begin{array}{c}\text { 平均 } \\
\text { 种植成本 } \\
\left(\text { 元 } / \mathrm{hm}^{2}\right)\end{array}$ & $\begin{array}{c}\text { 平均 } \\
\text { 抚育成本 } \\
\left(\text { 元 } / \mathrm{hm}^{2}\right)\end{array}$ & $\begin{array}{c}\text { 平均 } \\
\text { 采伐成本 } \\
\left(\text { 元 } / \mathrm{hm}^{2}\right) \\
\end{array}$ & $\begin{array}{l}\text { 劳动力 } \\
\text { 总成本 }{ }^{(6)} \\
\left({\left.\text { (元 } / \mathrm{hm}^{2}\right)}\right.\end{array}$ & $\begin{array}{l}\text { 生产资 } \\
\text { 料成本 } \\
\left(\text { 元 } / \mathrm{hm}^{2}\right) \\
\end{array}$ & & $\begin{array}{c}\text { 材积 } \\
\left(\mathrm{m}^{3} / \mathrm{hm}^{2}\right)\end{array}$ & $\begin{array}{l}\text { 预期收人 } \\
\text { 净现值 } \\
\left(\text { 元 } / \mathrm{hm}^{2}\right) \\
\end{array}$ \\
\hline \multirow{4}{*}{$\begin{array}{l}\text { 浙 } \\
\text { 江 } \\
\text { 省 }\end{array}$} & 普通户 & 17051 & 13025 & 9710 & 36137 & 17991 & 54128 & 127.2 & 84718 \\
\hline & 规模户 & 15728 & 14396 & 7929 & 33277 & 20736 & 54013 & 133.2 & 81611 \\
\hline & $T$ 均值检验 & 0.8 & -0.7 & 1.3 & 0.9 & $-2.9^{* * *}$ & -0.3 & -1.0 & 0.6 \\
\hline & 全部 & 16651 & 13440 & 9171 & 35273 & 18820 & 54093 & 130.2 & 83165 \\
\hline \multirow{4}{*}{$\begin{array}{l}\text { 福 } \\
\text { 建 } \\
\text { 省 }\end{array}$} & 普通户 & 12521 & 10912 & 15287 & 30758 & 26266 & 57024 & 187.9 & 140872 \\
\hline & 规模户 & 11142 & 15113 & 22045 & 37778 & 30080 & 67858 & 180.7 & 132848 \\
\hline & $T$ 均值检验 & 0.6 & $-2.1^{* *}$ & $-2.3^{* *}$ & $-2.1^{* *}$ & -1.6 & $-3.4^{* * * *}$ & 0.6 & 0.7 \\
\hline & 全部 & 12074 & 12274 & 17479 & 33035 & 27502 & 60538 & 184.3 & 136860 \\
\hline \multirow{4}{*}{$\begin{array}{l}\text { 江 } \\
\text { 西 } \\
\text { 省 }\end{array}$} & 普通户 & 13108 & 9447 & 16178 & 29913 & 24640 & 54547 & 128.8 & 69932 \\
\hline & 规模户 & 10880 & 6270 & 15019 & 26546 & 22273 & 48819 & 129.8 & 72070 \\
\hline & $T$ 均值检验 & 1.3 & $2.1^{* *}$ & 0.4 & 1.1 & 0.6 & 1.3 & -0.1 & -0.3 \\
\hline & 全部 & 12425 & 8473 & 15823 & 28880 & 23910 & 52791 & 129.3 & 71001 \\
\hline \multirow[t]{4}{*}{ 三省 } & 普通户 & 15668 & 12090 & 11682 & 34238 & 20424 & 54661 & 137.2 & 91253 \\
\hline & 规模户 & 14122 & 13166 & 11566 & 32938 & 22617 & 55555 & 140.9 & 88932 \\
\hline & $T$ 均值检验 & 1.2 & -0.8 & 0.1 & 0.6 & $-2.8^{* * * *}$ & -0.9 & -0.7 & 0.5 \\
\hline & 全部 & 15194 & 12420 & 11646 & 33839 & 21096 & 54936 & 139.05 & 90092.5 \\
\hline
\end{tabular}

现, 由于普通户较规模户具有更高的种植密度, 因此三省普通户的单位面积种植成本比 规模户高 $10.9 \%$ ，但两者并没有显著性差异。（2）抚育成本。该成本包括抗育期间的劳 动力成本和化肥、农药等生产资料成本。从调查中可以发现, 为促进杉木产出和收益, 规模户往往比普通户在抚育环节投人更多精力, 三省规模户平均单位面积抗育成本比普 通户高 $7.1 \%$, 尤其在福建省规模户平均单位面积抚育成本在 $1 \%$ 显著性水平上比普通户 高 $31.1 \%$ 。(3) 采伐成本。这部分主要是采伐阶段劳动力成本。规模户与普通户单位面 积采伐成本也没有显著性差异。从生产要素结构来分析，在单个轮伐期内，林农经营成 本主要包括两个部分：（1）劳动力成本。南方集体林区地形以丘陵为主，机械对劳动力 替代性较差, 整个营林过程需要投人大量劳动力成本, 3 个样本省户均单位面积劳动力 成本占总成本比例达到 $61.6 \%$ 。而三省规模户单位面积平均劳动力成本要小于普通户, 这符合规模经济特点；(2) 生产资料成本。包括了地租成本、种苗成本及其他生产资料 成本（主要包括化肥、农药、采伐设备中所需要的燃料成本）。由于规模户承包立地条件 质量较好的林地，往往承担更高的地租成本，因此规模户单位面积生产资料成本在 $1 \%$ 显 著性水平上比普通户高 $10.7 \%$ 。从预期营林收人净现值来看，规模户与普通户的林地单 位面积材积产出和预期收人净现值都没有显著性差异。

(6) 劳动力总成本包括自用工和雇工成本，其中自用工成本根据当地营林劳动力在某营林环节的市场价格作为影子 价格测算得到。劳动力价格随着营林环节有所区别, 2015 年浙江的造林抗育平均工价为 140 元/工, 采伐平均工价保持在 180 元/工; 福建的造林和抚育平均工价为 140 元/工, 采伐平均工价保持在 150 元/工; 江西的造林和抗育的平均工价为 100 元/工, 采伐平均工价保持在 120 元/工。 


\section{2 最优轮伐期和林地期望值测算}

根据杉木生长模型可以获取不同树龄 下的模拟蓄积和胸径，结合林农调查中获 取的营林各环节的投人产出数据, 采用 Faustmann 模型测算了林农最优轮伐期和林 地期望价值（表 3)。无论是普通户还是规 模户，在现有营林投人和 $2 \%$ 的贴现率下最 大地块杉木营林最优轮伐期都维持在 31 年 左右。但是不同地区规模户与普通户最大 地块最优轮伐期所对应的最优林地期望值 有一定的差异。三省平均而言，规模户 31 年树龄下的林地期望价值比普通户高 $3.1 \%$ ，除福建省外，一般而言规模户的林地投资价 值明显好于普通户，主要原因在于福建省规模户在最大地块上的一个周期内的单位面积 营林成本投人比普通户高 $19.2 \%$ 。

\section{3 非农就业对不同规模林农采伐决策影响的计量分析}

首先，对家庭户均非农时间、收人与林农预期主伐时间与理论最优轮伐期的离差进 行了交叉统计分析。从表 4 中可见，规模户随着家庭户均非农时间的延长和家庭人均非农 收人的增多，林农预期轮伐期与理论最优轮伐期的离差在缩小，即意味着规模户随着家 庭人均非农就业的增多，林农的预期营林采伐决策越与理论最优轮伐期接近，其采伐决 策会更优化；而普通户则相反，随着户均非农时间的延长，其预期主伐时间与理论最优 轮伐期的离差在增加，即意味着普通户非农就业时间的延长，会导致其提前采伐。

交叉统计无法判断非农就业对不同规模林农采伐决策的净影响，基于论文第二部分 中的计量模型形式和 NELM 理论，进一步分析非农就业对不同规模林农最大地块预期主 伐时间与理论最优轮伐期离差的影响机制（表 5)。总效应模型中：（1）关键变量方面,

\section{表 4 非农就业与不同规模林农最优轮伐期和预期轮伐期离差的交叉统计}

Table 4 The statistics between the deviation of optimal and expected rotation age and household samples' off-farming works

\begin{tabular}{|c|c|c|c|c|c|}
\hline \multirow{2}{*}{ 变量 } & \multirow{2}{*}{ 指标分类 } & \multicolumn{2}{|c|}{ 最大地块营林预期主伐时间(年) } & \multicolumn{2}{|c|}{ 最大地块预期主伐时间与理论最优轮伐期离差(年) } \\
\hline & & 规模户 & 普通户 & 规模户 & 普通户 \\
\hline \multirow{5}{*}{$\begin{array}{l}\text { 家庭户均 } \\
\text { 非农时间(月) }\end{array}$} & $\leqslant 1$ & 23.0 & 24.0 & 8.0 & 7.0 \\
\hline & $(1-3]$ & 23.5 & 23.5 & 7.5 & 7.5 \\
\hline & $(3-6]$ & 23.1 & 22.5 & 7.9 & 8.5 \\
\hline & (6-9] & 26.3 & 21.8 & 4.7 & 9.2 \\
\hline & $(9-12]$ & 21.5 & 21.7 & 9.5 & 9.4 \\
\hline \multirow{4}{*}{$\begin{array}{l}\text { 家庭人均非 } \\
\text { 农收人排名 }\end{array}$} & $\leqslant 25 \%$ & 25.3 & 24.2 & 5.7 & 6.8 \\
\hline & $(25 \% \sim 50 \%]$ & 23.2 & 23.0 & 7.8 & 8.0 \\
\hline & $(50 \% \sim 75 \%]$ & 22.9 & 21.5 & 8.1 & 9.5 \\
\hline & $(75 \% \sim 100 \%]$ & 22.9 & 22.1 & 8.1 & 8.9 \\
\hline
\end{tabular}

注：家庭人均非农收人排名是将样本户家庭户均非农收人由高到低进行排列，取前 $25 \% 、 25 \%$ $50 \% 、 50 \%$ $75 \% 、 75 \% \sim 100 \%$ 区间统计分析。 


\section{表 5 非农就业对不同规模林农营林采伐决策模型估计结果}

Table 5 The estimated results of off-farm works effect on harvesting decision of households

\begin{tabular}{|c|c|c|c|c|}
\hline \multirow{3}{*}{ 变量指标 } & \multicolumn{4}{|c|}{ 因变量：最大地块预期主伐时间与理论最优轮伐期离差(年) } \\
\hline & \multicolumn{2}{|c|}{ 分效应 } & \multicolumn{2}{|c|}{ 总效应 } \\
\hline & 规模户 & 普通户 & 规模户 & 普通户 \\
\hline \multicolumn{5}{|l|}{ 关键变量 } \\
\hline 家庭人均非农收人(千元) & $\begin{array}{l}-0.004^{* *} \\
(0.002)\end{array}$ & $\begin{array}{l}-0.005^{*} \\
(0.003)\end{array}$ & & \\
\hline 家庭成员平均非农时间(月) & $\begin{array}{c}0.175^{*} \\
(0.100)\end{array}$ & $\begin{array}{c}0.131^{* *} \\
(0.066)\end{array}$ & & \\
\hline 是否非农就业户 $(1=$ 是； $0=$ 否 $)$ & & & $\begin{array}{r}-1.575^{*} \\
(0.899)\end{array}$ & $\begin{array}{c}0.925^{*} \\
(0.548)\end{array}$ \\
\hline \multicolumn{5}{|l|}{ 地块经营特征变量 } \\
\hline 单位面积种植密度(株/亩) & $\begin{array}{l}0.018^{* * *} \\
(0.005)\end{array}$ & $\begin{array}{l}0.008^{* * *} \\
(0.003)\end{array}$ & $\begin{array}{c}0.016 \\
(0.005)\end{array}$ & $\begin{array}{l}0.008^{* *+} \\
(0.003)\end{array}$ \\
\hline 最大地块面积(亩) & $\begin{array}{r}-0.0004 \\
(0.001)\end{array}$ & $\begin{array}{l}-0.017 \\
(0.013)\end{array}$ & $\begin{array}{r}-0.0001 \\
(0.001)\end{array}$ & $\begin{array}{l}-0.020 \\
(0.013)\end{array}$ \\
\hline 最大地块离最近公路距离 $(\mathrm{km})$ & $\begin{array}{l}-0.113 \\
(0.092)\end{array}$ & $\begin{array}{c}0.033 \\
(0.101)\end{array}$ & $\begin{array}{l}-0.085 \\
(0.092)\end{array}$ & $\begin{array}{c}0.038 \\
(0.101)\end{array}$ \\
\hline \multicolumn{5}{|l|}{$\begin{array}{l}\text { 最大地块立地质量 } \\
\text { (以质量中等为参照组) }\end{array}$} \\
\hline 好 & $\begin{array}{c}1.313^{*} \\
(0.707)\end{array}$ & $\begin{array}{c}-0.433 \\
(0.486)\end{array}$ & $\begin{array}{c}1.427^{* *} \\
(0.714)\end{array}$ & $\begin{array}{c}-0.456 \\
(0.488)\end{array}$ \\
\hline 差 & $\begin{array}{c}1.606 \\
(1.169)\end{array}$ & $\begin{array}{l}-0.232 \\
(0.731)\end{array}$ & $\begin{array}{c}1.201 \\
(1.179)\end{array}$ & $\begin{array}{l}-0.173 \\
(0.735)\end{array}$ \\
\hline $\begin{array}{l}\text { 最大地块产权形式 } \\
\text { (承包山=1; 非承包山=0) } \\
\text { 外部政策变量 }\end{array}$ & $\begin{array}{c}1.907^{* *} \\
(0.837)\end{array}$ & $\begin{array}{l}1.534^{* * *} \\
(0.553)\end{array}$ & $\begin{array}{c}1.816^{* *} \\
(0.839)\end{array}$ & $\begin{array}{c}1.469^{m *} \\
(0.555)\end{array}$ \\
\hline 享受林业补贴政策(是=1；否=0) & $\begin{array}{l}-0.580 \\
(0.675)\end{array}$ & $\begin{array}{c}-0.117 \\
(0.503)\end{array}$ & $\begin{array}{c}-0.590 \\
(0.673)\end{array}$ & $\begin{array}{l}-0.225 \\
(0.502)\end{array}$ \\
\hline 林农家庭特征变量 & & & & \\
\hline $\begin{array}{l}\text { 家中是否有人担任村干部 } \\
(1=\text { 是； } 0=\text { 否) }\end{array}$ & $\begin{array}{c}0.286 \\
(0.699)\end{array}$ & $\begin{array}{l}-0.221 \\
(0.498)\end{array}$ & $\begin{array}{c}0.892 \\
(0.702)\end{array}$ & $\begin{array}{l}-0.268 \\
(0.500)\end{array}$ \\
\hline 户主受教育程度(以小学为参照组) & & & & \\
\hline 初中 & $\begin{array}{c}0.478 \\
(0.766)\end{array}$ & $\begin{array}{l}-0.498 \\
(0.511)\end{array}$ & $\begin{array}{c}0.746 \\
(0.772)\end{array}$ & $\begin{array}{l}-0.498 \\
(0.513)\end{array}$ \\
\hline 高中及以上 & $\begin{array}{c}0.242 \\
(1.627)\end{array}$ & $\begin{array}{l}-1.265 \\
(1.052)\end{array}$ & $\begin{array}{c}0.750 \\
(1.645)\end{array}$ & $\begin{array}{l}-1.402 \\
(1.058)\end{array}$ \\
\hline 户主年龄(年) & $\begin{array}{l}-0.052 \\
(0.039)\end{array}$ & $\begin{array}{l}-0.044 \\
(0.027)\end{array}$ & $\begin{array}{c}-0.054 \\
(0.040)\end{array}$ & $\begin{array}{l}-0.041 \\
(0.027)\end{array}$ \\
\hline 林业收人占家庭收人比例(\%) & $\begin{array}{l}-1.997^{*} \\
(1.039)\end{array}$ & $\begin{array}{l}-2.659^{* * *} \\
(0.952)\end{array}$ & $\begin{array}{r}-1.979^{*} \\
(1.085)\end{array}$ & $\begin{array}{l}-2.302^{* *} \\
(0.942)\end{array}$ \\
\hline 地域变量(以浙江省为参照组) & & & & \\
\hline 福建省 & $\begin{array}{l}-1.560 \\
(1.044)\end{array}$ & $\begin{array}{l}-2.867^{* * *} \\
(0.712)\end{array}$ & $\begin{array}{c}-2.520^{* *} \\
(1.125)\end{array}$ & $\begin{array}{c}-2.533^{\ldots *} \\
(0.716)\end{array}$ \\
\hline 江西省 & $\begin{array}{l}-2.673^{* *} \\
(1.030)\end{array}$ & $\begin{array}{l}-3.953^{* * *} \\
(0.691)\end{array}$ & $\begin{array}{c}-2.789^{* *} \\
(1.055)\end{array}$ & $\begin{array}{c}-3.532^{\ldots+\cdots} \\
(0.688)\end{array}$ \\
\hline 常数项 & $\begin{array}{c}5.706^{*} \\
(2.741)\end{array}$ & $\begin{array}{l}10.707^{* * *} \\
(2.020)\end{array}$ & $\begin{array}{l}7.339^{* *} \\
(2.933)\end{array}$ & $\begin{array}{l}10.038^{* * *} \\
(2.025)\end{array}$ \\
\hline 样本数 & 138 & 312 & 138 & 312 \\
\hline$R$-squared & 0.255 & 0.297 & 0.230 & 0.288 \\
\hline
\end{tabular}

注：“.”、“分别代表在 $1 \% 、 5 \% 、 10 \%$ 水平上显著，括号内为标准误差。 
在考虑其他因素不变情况下，非农就业的规模户对其预期主伐时间与理论最优轮伐期离 差在 $10 \%$ 水平上有负向影响，即非农就业可以促使规模户营林的预期主伐时间与最优轮 伐期接近，促使其采伐营林决策趋向最优化。而与之相反，在考虑其他因素不变情况 下，非农就业的普通户对其预期主伐时间与理论最优轮伐期离差在 $10 \%$ 水平上有正向显 著影响，即非农就业会造成普通户营林的预期主伐时间提前，从而远离最优轮伐期。 （2）其他控制变量方面: 在地块经营特征上, 在其他变量不变情况下，单位面积种植密 度与规模户和普通户的预期采伐时间与理论最优轮伐期离差都在 $1 \%$ 水平上呈显著正向影 响关系, 即种植密度越大, 采伐时间越提前, 这也说明了短周期的速生材和小径材以密 植为主的种植方式。最大地块产权形式是承包山的经营往往会导致预期主伐时间与理论 最优轮伐期离差显著增加。由于承包山往往有合同期限, 其产权存在一定的不安全性, 因此导致承包山的经营主往往提前采伐获取收益。福建省和江西省林农的预期主伐时间 与理论最优轮伐期显著小于浙江省, 这两个省份林农对用材林经营收人相对于浙江省更 加依赖; 在林农家庭特征变量上, 无论是规模户还是普通户, 随着林业收人占总收人比 例的加大，则其预期采伐时间与理论最优轮伐期离差在 $5 \%$ 水平上显著减小。即随着林业 收人依赖性的加大，农户对于林业经营决策会更加重视，因此其预期采伐时间更趋于优 化; 从区域变量来看, 相对于非农就业发达的浙江省, 福建省和江西省林农对于预期采 伐时间的选择更趋于合理, 即越接近于最优轮伐期。在分效应模型中可以进一步分解非 农就业对不同规模林农预期主伐时间与理论最优轮伐期离差的影响，从而获取非农就业 对不同规模林农采伐决策的影响存在差异性的原因。其他条件不变的情况下, 普通户平 均非农就业时间对其预期主伐时间与理论最优轮伐期离差在 5\%水平上有正向影响，基于 NELM 理论，可以认为非农就业的劳动力流失效应造成了普通户营林的预期主伐时间提 前, 远离最优轮伐期。而规模户的家庭人均非农收人对其预期主伐时间与理论最优轮伐 期的离差在 $10 \%$ 水平上有负向影响，则基于 NELM理论，认为非农就业的收人效应造成 了规模户的预期主伐决策更接近于理论最优的轮伐期。

\section{4 结论}

基于 NELM 理论和计量实证模型，可以发现，不同规模林农在面临非农就业情况下 会选择不同采伐期, 这也验证了本文在第二部分分析框架提出的理论假说, 并得到以下 结论:

（1）基于农户提供的杉木营林最大地块投人产出数据，普通户和规模户的理论最优 轮伐期趋同，但是不同案例点规模户与普通户最优林地期望值有一定差异。平均而言， 规模户的林地投资价值明显好于普通户。（2）非农就业的劳动力流失效应造成了普通户 营林预期主伐时间显著短于最优轮伐期。其原因有二：一是普通户在已经开展用材林经 营的背景下, 由于其非农就业造成的家庭劳动力流动性约束较紧, 会考虑提前采伐木 材, 这有助于节省采伐成本, 也可将营林劳动力配置到收益较高的非农就业上; 二是普 通户本身由于规模限制，正常或延后采伐带来的收益增加有限，也会导致其主伐时间提 前, 保证尽早收回成本。（3）规模户非农就业带来的收人效应造成了其采伐决策接近于 理论最优轮伐期。其原因一方面是由于非农就业带来的收人效应缓解了其流动性约束, 带来的家庭预算更为宽松（规模户户均家庭总收人是普通户的 2.6 倍），另一方面规模户 
经营面积大，随采伐时间延长所带来的规模效应可明显增加收益。从本文论证分析可发 现, 在中国农村劳动力非农转移就业加速的背景下, 从国家生态安全角度出发, 在南方 集体林区规模化经营方式有利于接近理论上最优采伐目标，更适合于培育大径材，增加 林业生态和经济效益, 也有利于保证木材供给安全。应通过建立林地流转平台、完善林 地流转承包办法等方式鼓励林地规模化经营，保障林地经营权; 鉴于目前非农就业带来 的农村劳动力成本不断上涨现实情况，为规模户提供林业造林和抚育补贴等方式鼓励规 模大户营林积极性。而对于普通农户而言，在非农就业造成流动性约束增加的情况下， 其用材林经营目标应有所调整，应选择更适合于速生短轮伐期的用材树种。

由于用材林经营具有营林周期长的特点，而农户的非农就业又存在很大的不稳定 性，因此难以收集长时间面板数据准确判断非农就业对农户的采伐决策影响，这也为林 业投人产出的相关领域研究带来挑战。本文基于营林成本主要集中于初始期的现实，根 据林农现阶段的非农就业情况和营林投人产出经验，探讨非农就业对其未来采伐决策的 影响, 并进行预估判断, 不失为一种有益的探索性研究。

\section{参考文献(References):}

[1] 侯一蕾, 王昌海, 吴静, 等. 南方集体林区林地规模化经营的理论探析. 北京林业大学学报: 社会科学版, 2013, 12(4): 1-6. [HOU Y L, WANG C H, WU J, et al. A theoretical analysis of forestland scale management in collective forest areas of south China. Journal of Beijing Forestry University: Social Science, 2013, 12(4): 1-6.]

[2] BUTLER B J, LEATHERBERRY E C. America's family forest owners. Journal of Forestry, 2004, 102(7): 4-9.

[3] ZHANG Y, ZHANG D, SCHELHAS J. Small-scale non-industrial private forest ownership in the United States: Rational and implications for forest management. Silva Fennica, 2005, 39(3): 443-454.

[4] 廖文梅, 孔凡斌, 林颖. 劳动力转移程度对农户林地投人产出水平的影响: 基于江西省 1178 户农户数据的实证分析. 林业科学, 2015, 51(12): 87-95. [LIAO W M, KONG F B, LIN Y. The impact of labor transfer level on input and output of household forestland-based production: A empirical analysis based on 1178 households in Jiangxi province. Science Silvae Sinicae, 2015, 51(12): 87-95.]

[5] 国家统计局. 2016年农民工监测调查报告. 北京: 国家统计局, 2017. [National Bureau of Statistics of China. China Migrant Workers Monitoring and Survey Report in 2016. Beijing: National Bureau of Statistics of China, 2017.]

[6] 柯水发, 王亚, 孔祥智, 等. 新型林业经营主体培育存在的问题及对策. 林业经济问题, 2014, 34(6): 504-509. [KE S F, WANG Y, KONG X Z, et al. The problems and countermeasures of cultivating new forestry management entities: Based on the survey in Zhejiang, Jiangxi and Anhui province. Issues of Forestry Economy, 2014, 34(6): 504-509.]

[7] 姚洋. 非农就业结构与土地租赁市场的发育. 中国农村观察, 1999, (2): 18-23. [YAO Y. Non-agricultural employment structure and development of land lease market. China Rural Survey, 1999, (2): 18-23.]

[8] KUNG K S. Off-farm labor markets and the emergence of land rental markets in rural China. Journal of Comparative Economics, 2002, 30(2): 395-414.

[9] QUISUMBING A, MCNIVEN S. Moving forward, looking back: The impact of migration and remittances on assets, consumption, and credit constraints in the rural Philippines. The Journal of Development Studies, 2010, 46(1): 91-113.

[10] 纪月清, 王亚楠, 钟甫宁. 我国农户农机需求及其结构研究: 基于省级层面数据的探讨. 农业技术经济, 2013, (7): 19-26. [JI Y Q, WANG Y N, ZHONG F N. Research on agricultural machinery demand and its structure in China: Based on provincial level data. Journal of Agrotechnical Economics, 2013, (7): 19-26.]

[11] MOCHEBELELE M T, WINTER N A. Migrant labor and farm technical efficiency in Lesotho. World Development, 2000, 28(1): 143-153.

[12] 钱文荣, 郑黎义. 劳动力外出务工对农户农业生产的影响: 研究现状与展望. 中国农村观察, 2011, (1): 31-37. [QIAN W R, ZHENG L Y. The impacts of labor migration on farm households' agricultural production: Literature review and future issues. China Rural Survey, 2011, (1): 31-37.]

[13] ADAMS R H J, ALFREDOl C. Remittances, household expenditure and investment in Guatemala. World Development, 
2010, 38(11): 1626-1641.

[14] BRAUW A D, ROZELLE S. Migration and household investment in rural China. China Economic Review, 2008, 19(2): 320-335

[15] XIE Y, GONG P C, HAN X, et al. The effect of collective forestland tenure reform in China: Does land parcelization reduce forest management intensity?. Journal of Forest Economics, 2014, 20(2): 126-140.

[16] FAUSTMANN M. Calculation of the value which forest land and immature in stands posses for forestry. Republished with permission from Commonwealth Forestry Association. Journal of Forest Economics, 1849, 1(1): 7-44.

[17] ANGELSEN A, KAIMOWITZ D. Rethinking the causes of deforestation: Lessons from economic models. World Bank Research Observer, 1999, 14(1): 73-98.

[18] ELLIS F. The determinants of rural livelihood diversification in developing countries. Agriculture Economics, 2000, 51: 289-302.

[19] 周国模, 郭仁鉴, 韦新良. 浙江省杉木人工林生长模型及主伐年龄的确定. 浙江农林大学学报, 2001, 8(3): $219-222$. [ZHOU G M, GUO R J, WEI X L. Growth model and cutting age of Chinese fir planted forest in Zhejiang province. Journal of Zhejiang A\&F University, 2001, 8(3): 219-222.]

[20] 杨雪春, 刘东兰, 郑小贤. 基于 GIS 的森林采伐辅助决策系统研究. 西北林学院学报, 2015, 30(4): 217-222. [YANG X C, LIU D L, ZHENG X X. Decision and development of support system for deforestation based on GIS. Journal of Northwest Forestry University, 2015, 30(4): 217-222.]

[21] 姜昕, 王秀娟. 森林的最优采伐决策模型: 一个新的林业经济政策分析框架. 林业科学, 2013, 49(9): 178-185. [JIANG X, WANG X J. Optimal harvest decision model for the forest: A new analysis framework to Chinese forestry economic policy. Scientia Silvae Sinicae, 2013, 49(9): 178-185.]

[22] 张英, 宋维明. 集体林权制度改革对农户采伐行为的影响. 林业科学, 2012, 48(7): 161-169. [ZHANG Y, SONG W M. Effect of collective forest tenure reform on people's harvesting behaviors. Scientia Silvae Sinicae, 2012, 48(7): 161169.]

[23] 朱臻, 沈月琴, 徐志刚, 等. 森林经营主体的碳汇供给潜力差异及影响因素研究. 自然资源学报, 2014, 29(12): 20132022. [ZHU Z, SHEN Y Q, XU Z G, et al. Research on the carbon supply potential capacity difference and its impact factors of forest management subjects. Journal of Natural Resource, 2014, 29(12): 2013-2022.]

[24] STAIBACK G A, ALAVALAPATI R R. Economic analysis of slash pine forest carbon sequestration in the southern U S. Journal of Forest Economics, 2002, 8(2): 105-117.

[25] STARK O, BLOOM D E. The new economics of labor migration. American Economic Review, 1985, 75(2): 173-178.

[26] FENG S. Land rental, off-farm employment and technical efficiency of farm households in Jiangxi province, China. NJAS-Wageningen Journal of Life Sciences, 2008, 55(4): 363-378.

[27] RUDEL T K, COOMES O T, MORAN E, et al. Forest transitions: Towards a global understanding of land use change. Global Environmental Change, 2005, 15(1): 23-31

[28] ZIMMERER K S. Soil erosion and labor shortages in the Andes with special reference to Bolivia, 1953-1991: Implications for "conservation-with-development". World Development, 1999, 21(10): 1659-1675.

[29] 刘承芳, 樊胜根. 农户农业生产性投资影响因素研究: 对江苏省六个县市的实证分析. 中国农村观察, 2002, (4): 3442. [LIU C F, FAN S G. A study on the factors affecting farmer's agricultural production investment. China Rural Survey, 2002, (4): 34-42.]

[30] OSENI G, WINTERS P. Rural nonfarm activities and agricultural crop production in Nigeria. Agricultural Economics, 2009, 40(2): 189-201

[31］国家林业局. 第八次森林资源清查. 北京: 国家林业局, 2015. [State Forestry Adminstration. China Forest Resource Statistics (8th National Forest Inventory). Beijing: State Forestry Administration, 2015.]

[32] 陈则生. 杉木人工林经济成熟龄的研究. 林业经济问题, 2010, 30(1): 22-26. [CHEN Z S. The research on age at economic maturity of Chinese fir plantations. Issues of Forestry Economics, 2010, 30(1): 22-26.]

[33] 朱臻, 沈月琴, 吴伟光, 等. 碳汇目标下农户森林经营最优决策及碳汇供给能力: 基于浙江和江西两省调查. 生态学: 报, 2013, 33(8): 2577-2585. [ZHU Z, SHEN Y Q, WU W G, et al. Household optimal forest management decision and carbon supply: Case from Zhejiang and Jiangxi provinces. Acta Ecologica Sinica, 2013, 33(8): 2577-2585.] 


\title{
Effect of off-farm employment on the harvesting decision-making of households with different scales in China's collective forest area
}

\author{
ZHU Zhen ${ }^{1,2}$, XU Zhi-gang ${ }^{3}$, SHEN Yue-qin ${ }^{2}$, ZHAN Jing ${ }^{4}$, LI Bo-wei ${ }^{1}$, CHEN Mei ${ }^{1}$ \\ (1. College of Economics and Management, Zhejiang Agriculture \& Forestry University, Lin'an 311300, \\ Zhejiang, China; 2. Zhejiang Province Key Cultivating Think Tank, Research Academy for Rural Revitalization \\ of Zhejiang Province, Zhejiang A\&F University, Lin'an 311300, Zhejiang, China; 3. College of Economics and \\ Management, Nanjing Agriculture University, Nanjing 210095, China; 4. Kaihua Forestry Administration, \\ Kaihua 324300, Zhejiang, China)
}

\begin{abstract}
To discuss how off- farm employment affect the harvesting decision- making of households with different scales in China's collective forest area is valuable to clarifying the forest management objectives for households and the trend of forest management ownership in collective forest area. This can give evidence for supporting the large-scale forest ownership under the background of the fast growing of out-migration rural labors in China. Based on the theory of New Economics of Labor Migration (NELM), this paper collected the input-output data at plot level of Chinese fir management through a survey of 50 rural households in Zhejiang, Fujian and Jiangxi provinces. Then, it calculated the optimal rotation age of largeand small-scale households with the Faustmann model, and used the econometric model to analyze how off-farm employment affect the harvesting decision-making of households with different scales. The results show that there is no obvious difference of optimal rotation age between large- and small- scale households. The migration effect of off- farm employment causing the expect rotation age is obviously smaller than optimal rotation age for small-scale households; on the contrary, the income effect of off- farm employment caused the expect rotation age is significantly closely related with optimal rotation age for large-scale households. Large-scale ownership is more suitable for raising large timbers and increasing economic and ecological value in collective forest area under the fast growing of out-migration rural labors in China.
\end{abstract}

Keywords: new economics of labor migration; collective forest area; harvesting decisionmaking; off-farm employment; Faustmann model 